\title{
Strategies Research on Face Culture Effect of College Students' Oral English Learning Efficiency \\ Yan Wu
}

\author{
Foreign Languages Department, Nanchang Normal University, Nanchang, Jiangxi 330002 , \\ P.R. China \\ ytaf_666@163.com
}

Keywords: Face culture; Negative effect; Oral English; Teaching strategies

\begin{abstract}
Face is people's positive social value basis they can efficiently earn for themselves in their social communications. But any coin has two sides: face-wants concept will also bring some negative effect to college students' oral English study. This paper tries to explore some oral English teaching strategies by virtue of analyzing the negative effects of the students' face-wants to the classroom teaching. We notice that appreciation-oriented teaching strategies and the individuality-respected assessment criteria can not only banish the face-wants negative impact to oral English teaching but can make the teaching more effective.
\end{abstract}

\section{Introduction}

With the arrival of 20th century when China has become one the world's great powers, the importance of international communication for China is increasingly requiring better oral communication abilities for Chinese college students. Even though, after years' of English courses from primary to middle schools, college students' English abilities such as grammatical analysis and question-answering has been substantially improved---this has been confirmed by the rising passing percentage of annual English level exams. In comparison, however, their spoken English communicative competence is absolutely in inferior position. Actually most of the college students' oral English communicative ability is very weak. Except some very common daily expressions they will be at a loss when communicative situations become more complicated. Though many factors have given rise to this phenomenon, the idea that they are in fear of losing face leads to the fact that they are reluctant and afraid of opening their mouth, fact that they negatively get involved into classroom oral practices. All this in turn causes the lack of confidence and study inefficiency for the students.

This article, based on face culture and theory, attempts to find relevant teaching tactics and evaluation methods by analyzing the negative influences of face ideas on learning efficiency for college students in their English oral study.

\section{Face Theory Literature Review}

Face is the base for one's self awareness and also a positive image one creates before the public. In sociology terminology, 'face' is a social identity people earn for themselves and accepted by others [1]. American sociologist Erving Goffman introduced the 'face' concept during the 50' in 20th century. He defined FACE as 'a positive social value earned by someone by speaking acts---a self image created based on highly-thought nature by society'. His theory of 'face work' defines face as a positive social value people effectively earn for themselves in their social communications. Face is also a kind of self image at its best. 'Face concept', as one of human behavior standards, has been widely followed in human behaviors, and those behaviors, in turn, are restricted by face [2]. British anthropologists Brown and Levison, in their some universals in language usage in 1978, also introduced face theory. They further divided face into two sides---positive face and negative face. [3].

Face is worth a thousand pieces of gold which has been widely realized in Chinese culture as an 
individual social value. Face culture has been influencing our routine social life to a greatest extent. In every dynasty, people from high officials to rank and files are very particular about what image they are in the eyes of others and take all possible behavior tactics and communication methods to earn and keep their own faces. Meanwhile he does the same to protect others' faces. Many domestic scholars such as Zhu Wanjin (1992), He Ziran (1998), He Zhaoxiong (2000) and Liu Huanhui (1997) undertook deep and multi-angle research on the influences of face culture on our language communications.

\section{Negative Influences of Face Culture on College Oral English Teaching}

Learning to freely and completely use a particular language is a long and painful process [4]. It is even all the more so for Chinese college students in oral language learning. This is because oral activities are more interactive, purposive, cultural and social, thus students need to get completely involved so as to reach the targets for both tasks and efficiency [5]. Entering college classrooms after many years of test-oriented education mode, not every student is completely psychologically and professionally prepared for college study. 'Face', this particular cultural and psychological phenomenon has brought about many negative influences to the students, who are confronted with difficulties and challenges at the same time.

Positive Face-Wants Leads to Anxiety and Tenseness. Positive face means that people expect their speech and ideas can get acknowledgment and approbation from their listeners (Brown \&Levinson, 1978: 62). During their junior to high school, students have been used to English teaching system oriented to tests only --- oriented by grammar analysis, short composition, words recitation and sentence pattern analysis while oral teaching is almost neglected. When they enter college, however, speaking lesson becomes something challenging. Due to the fact that they did not build good base for English speaking, students worry that their self-respect will be hurt because they will lose face before their teacher and classmates. Accordingly this tension and anxiety make them reluctant to get involved into classroom practice.

Negative Face-Wants leads to Negative and Passive Learning Attitudes. Negative face specifies a fact that people look for a freedom in communications, a fact that people do not want to be imposed upon, a fact that their acts are not interfered and hindered (Brown \& Levinson, 1978:66). Because they are poor in their English oral expression, students expect freedom in classroom---their acts are not interfered, hindered and imposed upon. They do not want to be asked questions, to show training tasks or to attend group discussion and speaking. However, oral teaching aim requires teachers to use language behaviors such as order, request, suggesting, and advices to organize their teaching, which will inevitably damage student's negative face and thus creates negative learning attitudes [6]. They will then negatively get involved into oral classroom training and reluctant to be cooperative accordingly.

\section{Constructive Strategies to Maintain Face-Wants Concept and Improve Oral English Teaching Efficiency}

When learners realize that there exists a huge gap between expression ability and learning objectives, their strategies tend to avoid those things beyond expression [7]. Avoiding those face-losing and embarrassing things during class allows students to passively join the classroom teaching process, which eventually affects their learning efficiency. It is a great challenge for teachers as how to create an easy, placid learning atmosphere for students so as to lessen their anxiety, frustration and strengthen their learning confidence and efficiency.

Lin Kelun, a famous US contemporary educational psychologist, thinks that an excellent teacher is not only knowledgeable, but also good at grasping psychological inter-activities between him and the students, and enhancing the teaching with positive psychological attitudes. US psychologist Smith also thinks that, even though the teaching methods are appropriate, them might not be able to lead the students into learning if they are not interested or not prepared with proper learning 
motives or recognition. William Littlewood points out that 'a teacher with sympathy and a cooperative class makes positive influence' (William Littlewood, 2000: 59). So teacher's attitudes, tactics for classroom correction and evaluation are vital to improving classroom atmosphere, eliminating negative effects to face-need and increasing teaching level.

Commendation-Oriented Teaching Strategies for Oral English Teaching. US psychologist James made a famous saying that "the most profound principle of human nature is that what he says or does can be appreciated by others. 'Appreciation education' can help the loser to regain confidence, to develop and rebuild the spiritual world, to retrieve the self-taught ability" [8]. He found in his research that appreciation is essentially a kind of inspiration. A man who has not been inspired can only release $20 \%-30 \%$ of his abilities. After he is inspired, however, he can release 3 or 4 times as much as that before he is done so. A teacher's respect and appreciation in the classroom can not only satisfy their essential desire of being appreciated, but also support and maintain their own positive face-need, which consequently makes students actively participate in classroom teaching. Undoubtedly appreciation education enhances students' confidence, supports and protects their face-need, exhibit their learning potentials and, most importantly, makes it no longer a hard question to improve oral English.

Creating Relaxed and Happy-Classroom Atmosphere. There are several points a teacher should note during his teaching to eliminate students' anxiety and tension and not to hurt their face-wants. First, tolerance should be the main criterion in the oral classroom. Teachers can't criticize or rebuke the students however imperfect their speaking ability is. Instead, teachers should smile in the classroom every day to create a relaxed, happy learning atmosphere so that students can be psychologically relaxed, and their confidence and enthusiasm for learning can be increased; secondly, teachers should pay attention to student's individual difference. This is because the essence of appreciation is to recognize differences, respect for differences, and encourage each student to get involved into curriculum teaching system; thirdly, the target requirements in the primary stage, does not need to be so high for the students even though there are wrong pronunciations and tones, even though they react very slowly in communication, even though they are all at sea in group practice... They deserve prompt praise and commendation as long as they open their mouths and cooperate in classroom activities.

Implementing Step-by-Step and Multiplex-Mode Teaching Strategies. The nature of oral English teaching is the interaction between teachers and students in cognition, emotion and will. It is also a cooperation process of cooperation between teachers and students in terms of these three elements. How this cooperation goes directly affects the teaching efficiency. This is because differences exist between everyone in their minds, oral English learning ability and personality, which sets up a great challenge to teaching strategies. First of all, a teacher should create a special English language environment and reach a consensus with the students that Chinese is spoken as little as possible in an oral English class. Although it is possible that the implementation will be disturbed in the process, the students at least know the basic principles of oral English learning --the learning tasks of each lesson and phase are to be completed by steps, in multiplex-mode and rich teaching strategies. Secondly, the form of teaching can be diversified: students can be divided into different groups to carry out a theme of practice like interactive dialogue, reading practice, group discussion or debate, role rehearsal or narration. In addition available teaching materials, teachers can also add some extracurricular topics for each class, which are not only suitable for students in their English level, but also dovetail with the needs of the students.

Construction of Individuality-Respected Classroom Error Correction and Evaluation System. People can't learn language very well without making mistakes, so the mistakes that students made in the practice of oral class can be tolerated and even ignored. The responsibility of teachers is to provide students with a continuous, complete communication space; to encourage them to build up their confidence and to participate in practices, to participate in classroom practices, not being afraid of making mistakes; only by this can they make progresses. However all 
this does not mean that teachers do not need to make assessment and correction of these mistakes. Instead, they must incorporate error correction and site assessment into classroom teaching. This is the only way that we can finish the task of oral English classroom teaching.

As mistake-correction - a speech act itself is the greatest harm to the listeners, teachers should learn how to complete the task of teaching and properly protect the face of the students at the same time. Goffman thought that, wherever the communication occurs and whatever relationship between the two sides, it is pretty sure that everyone's face should be supported and protected (Goffman, 1972:3). Without self-esteem, speakers will put his feelings into demonstration and protection of their faces; without care and consideration, speakers will make every effort to keep their faces and maintain other people's faces (William R. Cupach \& Sandra Metts, 1984:1-3). Therefore, error correction and evaluation system in oral English class should become a platform to respect students' individuality, to meet students' need of face-maintaining, to correct the errors in the students' oral expression and to improve the efficiency of oral English teaching.

Providing Self-Correction and Self-Assessment Opportunities for Every Student. Self-correct and self-assessment can not only inspire students to introspect but also can stimulate the interest in language learning [9]. The individual evaluation system should be combined with the method of" shallower-to-deeper" and horizontal/vertical comparison. This system should also take individual progress as the standard for verification and evaluation, which enables the students to feel their progress, to eliminate anxiety and to improve learning efficiency. Teachers should implement an implicit evaluation method for error-correction and site-assessment by respecting students' self-esteem, protecting their psychological need for face [10].

In the practice process of passage reading, imitation dialogue, group discussion, topic performance, teachers can join as a member or a role in the discussions and write down each one's problems and errors, but not implement error correction and evaluation right away, which can be done by individual guidance at right time. Once the students' anxiety and tension relieves and their learning attitudes get back to normal in the classroom training, the students can be led mutual-correction and evaluation procedure. This will provide a platform for them to take the initiative, to know themselves, to look at themselves as well as to enhance their confidence. This individual-difference-respective mode can release the psychological burden of the students, making them desired to participate in free communication and oral classroom teaching system.

Providing Class-Management Platform for Overall Correction and Assessment. Teachers can implement student-assessment during the class or in a certain period of teaching. It is an essential tenet for classroom error-correction and evaluation that students' spoken language knowledge, skills, cultural awareness are evaluated in a dynamic view. What is more, this evaluation system is supposed to be continuous but not instant (NIC Underhill, 1987:27).

In addition to providing students with implicit correction and evaluation opportunities, teachers should also make classification and analysis of each student's problems, mistakes, relevant corrections, and then explain to the whole class in detail at appropriate time demonstrating and providing corresponding correction strategies. At the end of a semester, a comprehensive evaluation and summary must be made on the learning targets of this semester. Meanwhile commendation on improvement from the students should be combined with individual error-correction so as to make the whole class become aware of the problems during oral communication and know exactly their individual problems, objectives and rules. All this is means a lot to the efficiency of classroom learning.

\section{Conclusion}

We found from the research that appreciation-teaching-strategies for face-protection and individual-respect-evaluation system can guide students to establish a positive psychological quality in oral English teaching and face the difficulties and problems with a rational attitude. It also enables them to actively get involved into teaching and to improve learning efficiency.

Face is a human phenomenon. It is a special cultural and psychological phenomenon in which 
people protect their self-dignity in social communication situations. Face saving, face earning and face protection are normal psychological needs and dignity for human being. In English speaking teaching - a unique language communication situation easy to make one feel anxious and worried, the goal of real classroom teaching should be a comprehensive utilization of various teaching methods and teaching strategies. In addition to appreciation teaching and individual-respect evaluation system to maintain the students' face, other options for teaching strategies and evaluation methods should also serve this main teaching purpose and task. To eliminate the negative influences of face culture on oral English teaching is helpful to improving the efficiency of oral English teaching.

\section{References}

[1] WilliamR. Cupach \&Sandra Metts, Facework[M] SAGE Publications, Inc.UK, 2012:1-3

[2] Erving Goffman, Interaction Ritual: Essays on face-to-face Behaviour [M] London: Allen Lane The Penguin Press ,2013:3-5

[3] Penelope Brown\& Stephen Levinson.,Politeness: Some universals in language usage [M] Cambridge: Cambridge University Press, 2013:62

[4] Wilga M. Rivers\& Mary S, Temperley, A Practical Guide to the Teaching of English as a Second Language [M] New York Oxford University Press, 2012:vii

[5] Yan Wu, On Oral English classroom Instruction Efficiency---An empirical investigation report[J] Jiangxi Educational Institute Journal 2013(4):38-42

[6] Olshtain, .E. \& Gohen, A. D Teaching Speech Act Behavior to Nonnative Speakers. In M. Celee Murcia (Ed). Cambridge MA : Newbury House Harper and Row,2013:26-86

[7] William Littlewood, Foreign and Second Language learning[M]Foreign Language Teaching and Research Press\& Cambridge University Press ,2013:59-83

[8] Minmin Huang Modern psychology [M] Beijing:China Publication Press2012:300-326

[9] Nic Underhill. Testing Spoken English: A handbook of Oral Testing Techniques [M] Cambridge: Cambridge University Press ,2014:23-27

[10]Ronghua Shi Social-psychology [ M ] Hangzhou:Zhejiang Education Press, 2012:138-141 